\title{
A Comparative Study on the Larval Life History in Two Populations of Hynobius boulengeri from Kyushu, Japan (Amphibia: Urodela)
}

\section{$\operatorname{AUTHOR}(S)$ :}

Nishikawa, Kanto; Matsui, Masafumi

\section{CITATION:}

Nishikawa, Kanto ...[et al]. A Comparative Study on the Larval Life History in Two

Populations of Hynobius boulengeri from Kyushu, Japan (Amphibia: Urodela). Current Herpetology 2008, 27(1): 9-22

ISSUE DATE:

2008-06

URL:

http://hdl.handle.net/2433/216833

RIGHT:

(C) 2008 by The Herpetological Society of Japan 


\title{
A Comparative Study on the Larval Life History in Two Populations of Hynobius boulengeri from Kyushu, Japan (Amphibia: Urodela)
}

\author{
KANTo NISHIKAWA AND MASAFUMI MATSUI* \\ Graduate School of Human and Environmental Studies, Kyoto University, Yoshida \\ Nihonmatsu-cho, Sakyo-ku, Kyoto 606-8501, Japan
}

\begin{abstract}
We compared larval life history between two populations of Hynobius boulengeri from Kyushu, Japan, one from Takachiho on the SoboKatamuki Mountains and the other from Kinko on the Osumi Peninsula. They showed variation in life history which seems to be induced partially by differences in water temperature and food availability, but may also reflect differences at the genetic level. Larvae from Takachiho, where the water temperature was lower in winter, developed more slowly but grew more quickly under higher summer temperatures and by eating larger prey than larvae from Kinko. In Takachiho, most larvae overwintered once or twice, and in one case, three times. In contrast, larger numbers of larvae metamorphosed without overwintering in Kinko. Takachiho larvae were larger at metamorphosis $(\mathrm{SVL}=$ ca $39 \mathrm{~mm}$ in average) than Kinko larvae (ca. $31 \mathrm{~mm}$ ), and this difference is thought to affect the body size difference in adults. The relatively large mouth in Takachiho larvae is thought to be an adaptation not to cannibalism, but to larger prey. The relatively small mouth in Kinko larvae, unique among larvae of $H$. boulengeri populations and its ally, $H$. hirosei, seems to be also constrained by genetic factors.
\end{abstract}

Key words: Hynobius boulengeri; Larval life history; Growth pattern; Age; Size at metamorphosis; Diet.

\section{INTRODUCTION}

As in many other animals, variations in life history are known to affect intraspecific morphological variations, such as variation in body size, in urodeles (Bruce, 1989; Juterbock, 1990; Tilley and Bernardo, 1993; Misawa and Matsui, 1997; Bernardo and Agosta, 2003).

\footnotetext{
* Corresponding author. Tel/Fax: +81-75-7536846;

E-mail address: fumi@zoo.zool.kyoto-u. ac.jp
}

Hynobius boulengeri (Thompson, 1912) is a salamander indigenous to the southwestern part of the Japanese mainland (Honshu, Shikoku, and Kyushu Islands) (Sato, 1954) and occurs around mountain streams. The species, with a total length reaching $200 \mathrm{~mm}$ (Matsui, 2000), was long known as the largest among Japanese Hynobius (Sato, 1943), but this image has changed recently. We found two isolated populations of $H$. boulengeri on Kyushu, one on the Osumi Peninsula and the other on the Amakusa Islands (Fig. 1), that 


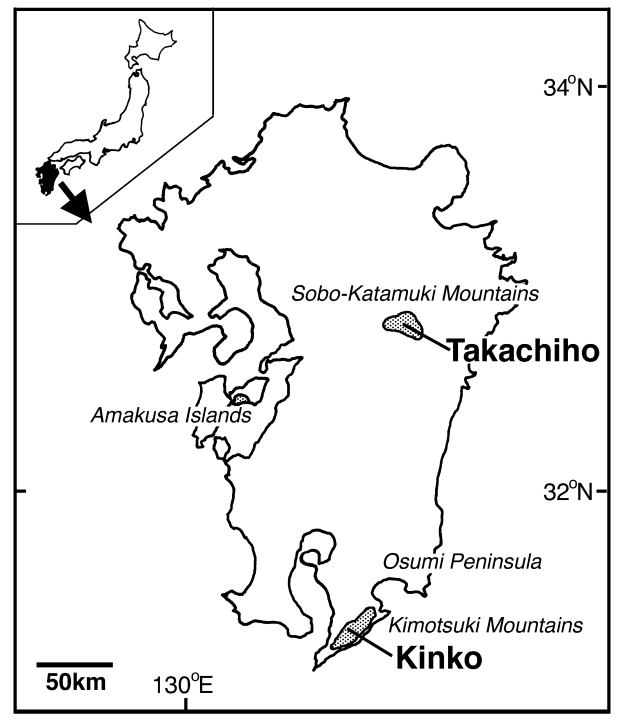

Fig. 1. A map of Kyushu, Japan, and study sites. Shaded areas show the distribution range of Hynobius boulengeri in Kyushu (after Nishikawa et al., 2003).

form a genetically well supported clade with the remaining Kyushu population from SoboKatamuki Mountains, but are significantly smaller in adult body size than the latter (Nishikawa et al., 2001, 2003, 2005). The larvae of these two populations were also much smaller than those of the SoboKatamuki population (Fig. 2; Nishikawa et al., 2003; Sato, 2003).

These differential larval and adult body sizes found in $H$. boulengeri from Kyushu might be induced by their differential larval growth and development, which in turn are expected to be affected by differential environmental factors (Berven and Gill, 1983; Misawa and Matsui, 1997; Iwasaki and Wakahara, 1999). In addition, genetic factors, singly or combined with environmental factors, have also been reported to contribute to variations in these larval traits in a few other amphibians (Berven, 1982; Bernardo, 1994). As mentioned above, our previous genetic analyses indicated that the three $H$. boulengeri populations from Kyushu form a cluster, splitting from conspecific populations in the other regions of Japan.

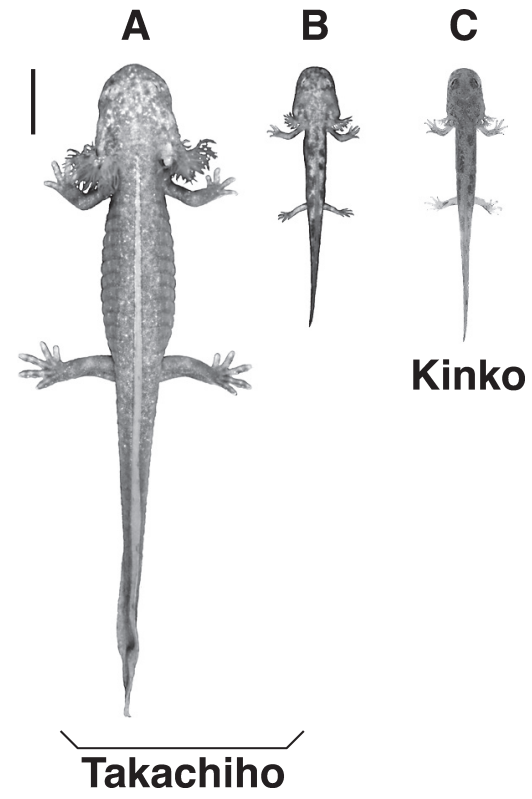

FIG. 2. A fourth-year larva from Takachiho (A, St. 66) collected in early May, and first-year larvae from Takachiho (B, St. 62) and Kinko (C, St. 63) collected in mid June. Note the wider head relative to body length in B compared to $\mathrm{C}$. The scale bar is $10 \mathrm{~mm}$.

Within Kyushu, however, the Osumi and Amakusa populations are genetically fairly remote from the Sobo-Katamuki population (Nishikawa et al., 2005).

In this study, we compare patterns of larval growth and development between populations of $H$. boulengeri from Osumi Peninsula and Sobo-Katamuki Mountains and discuss factors that might affect these patterns.

\section{MATERIALS AND METHODS}

Between 1995 and 2003, we made 18 visits to one small tributary of the Iwato River in the Sobo-Katamuki Mountains, Takachiho-cho $\left(32^{\circ} 45^{\prime} \mathrm{N}, 131^{\circ} 23^{\prime} \mathrm{E}, 550 \mathrm{~m}\right.$ alt.), Miyazaki Prefecture and 11 visits to another tributary of the O River in the Kimotsuki Mountains of Osumi Peninsula, Kinko-cho (formerly Tashirocho: $31^{\circ} 08^{\prime} \mathrm{N}, 130^{\circ} 53^{\prime} \mathrm{E}, 610 \mathrm{~m}$ alt.), Kagoshima Prefecture (Fig. 1). In Takachiho, the study 
site is located in a forest partly consisting of artificially planted Japanese cedars, with dominance of evergreen shrubs and broadleaf trees along the stream. The stream $(<4 \mathrm{~m}$ wide) was very steep with many waterfalls $(<3.5 \mathrm{~m}$ high) and pools ( $<1.5 \mathrm{~m}$ deep) whose bottom was covered with hard volcanic rocks. On the bottom of pools, fallen leaves were piled throughout the year. The surface of the stream was open, without covering by the surrounding trees. By contrast, the stream in Kinko was much less steep than in Takachiho, with smaller waterfalls $(<1 \mathrm{~m}$ high) and shallower pools ( $<30 \mathrm{~cm}$ deep), and was widely covered by Japanese cedars and other evergreen trees, resulting in shaded surfaces even in the daytime. The ground along the study site consisted of granite, and the bottom of the stream was covered with granite sand. Because of the geomorphology, the water current was gentle in most parts of the stream and ran underground in places.

In all seasons, we collected larvae between 2100 and $2400 \mathrm{~h}$ when they were found active on the streambed. Larvae caught by a dip net or fished were deeply anesthetized with saturated Chloreton (acetone chloroform) solution and then fixed in $10 \%$ formalin, for later taxonomic purposes (see Nishikawa et al., 2001 and 2003). For analyses of stomach contents, the stomach flushing technique is preferable. However, this method was not easily applied to such small animals as the $H$. boulengeri larvae. Moreover, we needed femur samples for skeletochronology (see below). Thus, we sacrificed a minimal number of specimens for our purpose (94 from Takachiho and 97 from Kinko over nine years). Specimens were later preserved in $50 \%$ ethanol, and stored at the Graduate School of Human and Environmental Studies, Kyoto University (KUHE).

We measured water temperature to the nearest $0.1 \mathrm{C}$ with a digital thermometer (D617; TECHNOL SEVEN Corp., Japan) at the start of each larval survey (around $2100 \mathrm{~h}$ ). We also set up a data logger (StowAway TidbiT Temp Logger; Onset Computer
Corp., USA) at each site to record the water temperature at $2100 \mathrm{~h}$ every day between June 2003 and May 2004.

For each of the preserved specimens, we determined the developmental stage following the table proposed for the congeneric species H. nigrescens Stejneger, 1907 (Iwasawa and Yamashita, 1991) where stages (Sts.) 50 to 62, 63 , and 64 to 68 , respectively, correspond to: 1) from early stage of digital differentiation until the membrane between each toe beginning to disappear, 2) full-grown (the membrane between each toe disappears), and 3) from onset to completion of metamorphosis. It was very difficult to collect individuals just metamorphosed in the field because they seemingly disperse soon after transformation. However, since the larvae complete metamorphosis shortly after stage 64 (Iwasawa and Yamashita, 1991), we regarded the date of appearance of these larvae as approaching metamorphosis.

We measured snout-vent length (SVL: from the tip of the snout to the anterior margin of the cloaca) and mouth width (MW: distance between angles of jaws) of the preserved specimens using a digital caliper (CD-20CP; Mitsytoyo Corp., Japan) to the nearest $0.1 \mathrm{~mm}$. We also measured wet body mass (BM) using a digital balance (1476; TANITA Corp., Japan) to the nearest $1 \mathrm{mg}$ after wiping off the surface water. We examined relationships of MW and BM with SVL by ANCOVA using $\log _{10^{-}}$ transformed values.

Because our sampling schedule varied from year to year and larval body size varied extensively, we could not classify larvae into clear age classes by their body size alone. In order to determine the accurate age of each larva, we therefore used skeletochronology, which is currently widely utilized for this purpose in amphibians (Castanet and Smirina, 1990; Smirina, 1994: but see Eden et al., 2007). We prepared cross-sections (ca $25 \mu \mathrm{m}$ thick) of femurs using a freezing microtome and stained them with hematoxylin (Mayer's acid hemalum), basically following Misawa and Matsui (1999). Under a light microscope 
at $400 \mathrm{X}$ magnifications, we chose sections from the central regions of the diaphysis and counted lines of arrested growth (LAGs).

In several other congeners, LAGs are known to be formed in seasons when bones have low growth rates (Misawa and Matsui, 1999; Ento and Matsui, 2002), and we thus assumed the number of LAGs as the number of overwinterings. If the lines observed were not clear or ambiguous, we sectioned other bones to obtain clearer results. Because a new LAG may have been formed up to several months after hibernation (Ento and Matsui, 2002), we carefully examined the fully-grown larvae collected in early spring to ascertain whether or not a cryptic LAG was present at the outer margin of the bone. In describing larval growth and development, we classified larval age by setting the year of hatching as the first year, and 1 January of the first year as day 1 .

For stomach content analyses, we dissected specimens preserved in ethanol. Items vomited by larvae before fixation were excluded from the analyses. We identified stomach contents to the lowest practical taxonomic level, which was usually to the class or order. We measured maximum length and width of each item to the nearest $0.1 \mathrm{~mm}$ using either a caliper or a calibrated ocular micrometer fitted to a dissecting microscope. For partially digested prey items, we estimated the original size from regressions predetermined from intact prey. Volumes of prey items were calculated using the formula for an ellipsoid (Dunham, 1983): $\mathrm{V}=4 / 3 \pi(\mathrm{L} / 2)(\mathrm{W} / 2)^{2}$.

We compared frequencies of occurrence of all prey taxa between larvae from the two sites by Fisher's exact probability test. We also quantified dietary overlap by calculating Morishita's (1959) similarity indices: $C \lambda=$ $2 \Sigma x i y i /[(\lambda x+\lambda y) \Sigma x i \Sigma y i]$, where $\lambda x=\Sigma x i(x i-1) /$ $\Sigma x i(\Sigma x i-1), \lambda y=\Sigma y i(y i-1) / \Sigma y i\left(\sum y i-1\right)$, and $x i$ and yi are the number of stomach contents for sites $\mathrm{x}$ and $\mathrm{y}$ in category $\mathrm{i}$, respectively. At the same time, niche breadth was calculated by Shannon-Weaver's index (H': Shannon and Weaver, 1949): $\mathrm{H}^{\prime}=-\Sigma \mathrm{Pi} \ln \mathrm{Pi}$, where $\mathrm{Pi}$ is the frequency of category $i$.
We estimated relationships between predator and prey sizes by regressing mean lengths of prey in a stomach to larval SVL and MW by ANCOVA. In order to eliminate sampling bias, only larvae with at least three prey items in their stomachs were included in this analysis. We used SAS (SAS, 1990) for statistical analyses. All analyses were made using $\mathrm{P}<0.05$ as significant.

\section{RESULTS}

\section{Water temperature}

In Takachiho, water temperatures varied greatly from $2.8 \mathrm{C}$ in January to $19.4 \mathrm{C}$ in July (fluctuation range $=16.6 \mathrm{C}$, Fig. 3). The water temperatures in Kinko fluctuated much less than in Takachiho, from 7.2 C in January to 17.3 $\mathrm{C}$ in September (fluctuation range $=10.1 \mathrm{C}$, Fig. 3). Between June and August, the water temperatures were higher in Takachiho than in Kinko, although in the other months of the

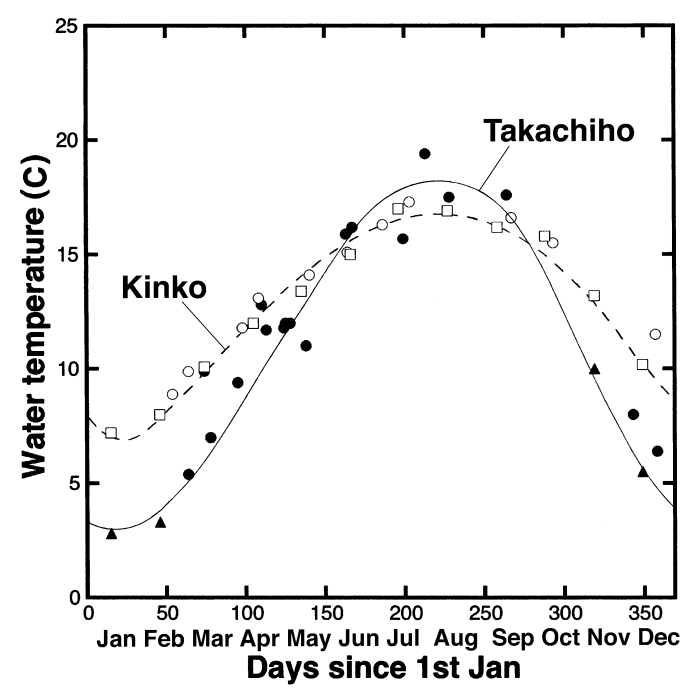

Fig. 3. Annual fluctuations in water temperatures at the two study sites. Temperatures recorded in Takachiho and Kinko at each survey are shown by closed and open circles, respectively. Mean monthly temperatures recorded at a trout farm near the Takachiho study site and those recorded by data logger in Kinko are shown by closed triangles and open squares, respectively. 
year, this relationship was reversed, and temperatures were much lower in Takachiho than in Kinko.

\section{Age determination}

Hatchlings, judged from their developmental stages, SVL, and BM, appeared in early May in Takachiho and in mid April in Kinko (see below). Thus, the larger larvae collected before this season (between January and April) in the two sites were presumed to have overwintered. We found at least one LAG in all of these larvae, except for a few individuals $(\mathrm{n}=2$ in Takachiho and $\mathrm{n}=3$ in Kinko). Because these latter larvae were fully-grown or just metamorphosing (St. 63 or older) like others, we judged them to have overwintered, but in the state before formation of a LAG. Indeed, in the LAGs actually observed in the rest of the larvae, the outermost one was positioned very close to the margin of the bone, suggesting its recent formation. When LAGs of all larvae including those collected in other seasons were examined, the number of LAGs differed between the two sites $(0-3$ in Takachiho and 0-1 in Kinko).

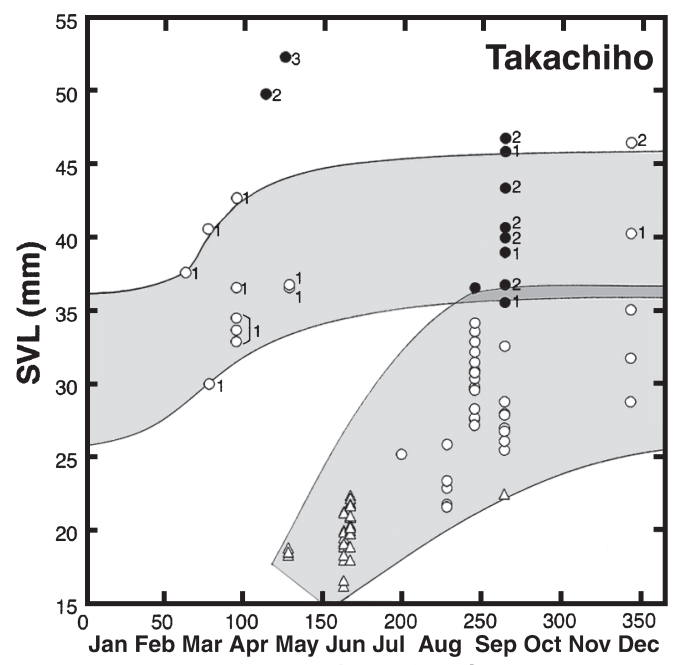

Days since 1st Jan

\section{Growth and development in Takachiho}

On the basis of ages estimated above, growth in SVL of larvae against the time of the year is shown in Fig. 4, in which larvae with different ages are shown separately. The youngest larvae of the first year (Sts. 58-59: Table 1) were observed from early May to mid June. Full-grown larvae of St. 63 appeared in mid July and predominated thereafter until the end of the year. Larvae at St. 63 were highly variable in body size, with SVL and $\mathrm{BM}$ ranging from 21.6-35.1 $(\mathrm{x} \pm \mathrm{SD}=28.58 \pm 3.47)$ $\mathrm{mm}$ and from 341-1753 (709.4 \pm 290.8$) \mathrm{mg}$, respectively, among all first-year larvae $(n=34)$. Larvae of this stage (63) continued growth from early-late September to early December in mean BM, although their mean SVL did not increase much during this period (see Table 1).

In the first year, means of SVL and BM between early May and early December increased 1.7 and 5.8 times, respectively, and the growth rate in this period was roughly estimated to be $0.06 \mathrm{~mm} /$ day in SVL, and $5.8 \mathrm{mg} /$ day in BM (Table 1). All larvae of the first year, except one, which reached St. 64 in early September, remained at St. 63 and never

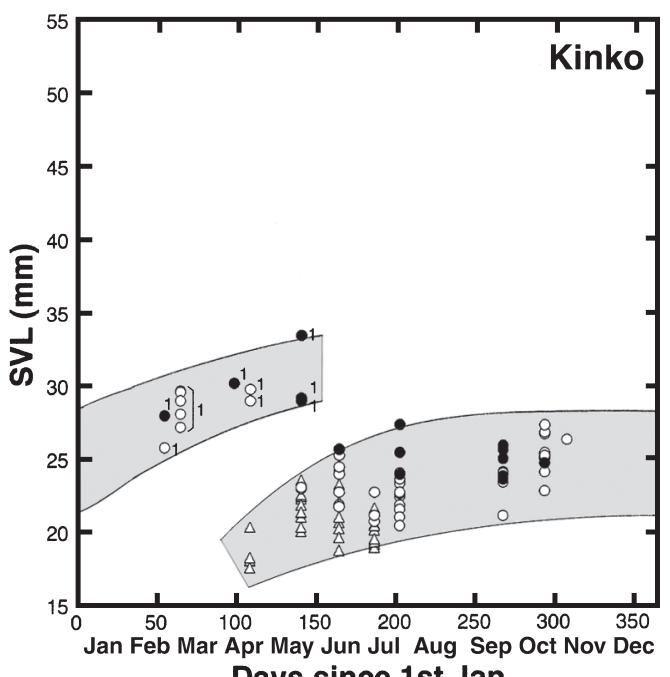

Days since 1st Jan

FIG. 4. Growth of larval SVL against date of collection (1=1 January) in the two study sites, Takachiho and Kinko. Open triangles, open circles, and closed circles represent individuals of St. $<63,63$, and $>63$, respectively. Numbers beside plots indicate the age estimated by skeletochronology. Shaded areas show the estimated SVL ranges until the second overwintering. 
TABle 1. Growth in the two study sites. Measurements are given as $\mathrm{x}+\mathrm{SD}$, followed by range in parenthesis.

\begin{tabular}{|c|c|c|c|c|c|}
\hline Age & Date (days from 1 Jan of the 1st yr) & Stage & $\mathrm{n}$ & SVL (mm) & $\mathrm{BM}(\mathrm{mg})$ \\
\hline \multicolumn{6}{|c|}{ Takachiho } \\
\hline \multirow[t]{10}{*}{1 st yr } & early May-middle Jun (128-167) & 58,59 & 11 & $19.25 \pm 1.33$ & $236.18 \pm 37.00$ \\
\hline & & & & $(16.6-21.3)$ & $(187-310)$ \\
\hline & middle July (199) & 63 & 1 & 25.2 & 660 \\
\hline & middle Aug (228) & 63 & 6 & $23.58 \pm 1.92$ & $493.00 \pm 157.19$ \\
\hline & & & & $(21.6-25.9)$ & $(341-730)$ \\
\hline & Sep (245-264) & 63 & 24 & $29.55 \pm 24.8$ & $786.91 \pm 186.13$ \\
\hline & & & & $(25.5-34.2)$ & $(558-1260)$ \\
\hline & early Dec (343) & 63 & 3 & $31.90 \pm 3.15$ & $1376.33 \pm 382.11$ \\
\hline & & & & $(28.8-35.1)$ & (989-1753) \\
\hline & early Sep (245) & 64 & 1 & 36.6 & 1576 \\
\hline \multirow[t]{4}{*}{ 2nd yr } & middle Mar-middle May (443-503) & 63 & 10 & $36.20 \pm 3.69$ & $2165.20 \pm 662.99$ \\
\hline & & & & $(30.0-42.7)$ & $(1210-3570)$ \\
\hline & late Sep (629) & $67-68$ & 3 & $40.17 \pm 5.24$ & $1828.33 \pm 754.08$ \\
\hline & & & & $(35.6-45.9)$ & $(1265-2685)$ \\
\hline \multirow[t]{3}{*}{$3 \mathrm{rd} y r$} & late Apr (843) & 65 & 1 & 49.8 & 4435 \\
\hline & late Sep (994) & $65-68$ & 5 & $41.54 \pm 37.6$ & $1935.00 \pm 534.65$ \\
\hline & & & & $(36.8-46.8)$ & $(1215-2575)$ \\
\hline 4th yr & early May (1220) & 66 & 1 & 52.3 & 6670 \\
\hline \multicolumn{6}{|l|}{ Kinko } \\
\hline \multirow[t]{8}{*}{1 st yr } & middle Apr (108) & 57,58 & 4 & $18.60 \pm 1.24$ & $240.5 \pm 26.59$ \\
\hline & & & & $(17.6-20.4)$ & $(216-276)$ \\
\hline & late May-late Jul (140-202) & 63 & 24 & $22.85 \pm 1.36$ & $408.88 \pm 55.68$ \\
\hline & & & & $(20.5-25.7)$ & $(310-490)$ \\
\hline & late Sep-early Nov (267-307) & 63 & 13 & $24.89 \pm 1.79$ & $627.85 \pm 165.61$ \\
\hline & & & & $(21.2-27.4)$ & $(304-875)$ \\
\hline & late Sep-early Nov (267-307) & $64-66$ & 7 & $25.00 \pm 0.91$ & $597.86 \pm 53.70$ \\
\hline & & & & $(23.7-26.0)$ & $(532-694)$ \\
\hline \multirow[t]{4}{*}{ 2nd yr } & late Feb-late May (419-505) & 63 & 9 & $28.64 \pm 1.37$ & $936.56 \pm 155.27$ \\
\hline & & & & $(25.8-29.8)$ & $(690-1100)$ \\
\hline & late Feb-late May (419-505) & $65-68$ & 6 & $29.63 \pm 2.10$ & $960.17 \pm 203.60$ \\
\hline & & & & $(27.8-33.5)$ & $(655-1275)$ \\
\hline
\end{tabular}

approached metamorphosis in that year. The single exceptional individual was longest and second heaviest among the first-year larvae.

The second-year larvae (with one LAG) were fewer than the first-year larvae. Of these, the larvae at St. 63 collected in spring tended to be larger than the larvae of the same stage before overwintering though the difference was not significant $\left(\mathrm{t}_{11}=1.81, \mathrm{P}=0.103\right.$ in SVL, $\mathrm{t}_{11}=1.93, \mathrm{P}=0.082$ in $\mathrm{BM}$ ) probably because of small sample size in early winter $(n=3)$.

Among the second-year larvae, individuals approaching or completing metamorphosis (St. 67-68) were found in late September. They did not grow much since St. 63 in the earlier part of the year (mid March to mid 
May). Larvae of the third year were even fewer than the second-year larvae. Some of them were found at the same time in late September with metamorphosing second-year larvae, and were also at Sts. 65-68. Means of their SVL and BM were similar to those observed in the second-year individuals $\left(\mathrm{t}_{6}=\right.$ $0.44, \mathrm{P}=0.680$ in $\mathrm{SVL}, \mathrm{t}_{6}=0.24, \mathrm{P}=0.821$ in $\mathrm{BM})$. Another individual of the third year collected in spring (late April) was also approaching metamorphosis, but was much larger than the autumn samples (Table 1). Similarly, the single fourth-year individual found in spring (early May), was very large, with the maximum size both in SVL and BM among larvae of the Takachiho population (Fig. 2A. Table 1).

Metamorphosing larvae (St. 68) of the second and third years were found in late September. The second-year larvae $(n=2$, mean $\mathrm{SVL}=37.3 \mathrm{~mm}$, mean $\mathrm{BM}=1400.0 \mathrm{mg}$ ) and the third-year larvae $(n=3$, mean $\mathrm{SVL}=$ $40.3 \mathrm{~mm}$, mean $\mathrm{BM}=1645.0 \mathrm{mg}$ ) had similar body size and showed no marked growth.

In summary, larvae of the Takachiho population usually overwinter once, and show reduced growth rate in the second year. They normally metamorphose after late September of the second or the third year with the SVL around $37-40 \mathrm{~mm}$ and BM about 1400$1645 \mathrm{mg}$. Only a few individuals that have already reached this size metamorphose after early September of the first year, or after late April or early May of the third or fourth year at a larger size $(\mathrm{SVL}=50-52 \mathrm{~mm}, \mathrm{BM}=4400$ $6700 \mathrm{mg}$ ).

\section{Growth and development in Kinko}

In Kinko, the youngest individuals (Sts. 57 and 58) were found in mid April (Table 1). Some larvae reached St. 63 in late May, but younger ones of St. 62 were observed thereafter until early July. Between late May-late July and September-early November, larvae of St. 63 increased mainly in BM (Table 1), and larvae at this stage in the first year $(n=37)$ varied from $20.5-27.4(\mathrm{x} \pm \mathrm{SD}=23.6 \pm 1.8) \mathrm{mm}$ in SVL and from 304-875 (485.8 \pm 149.5$) \mathrm{mg}$ in
BM. When all stages are combined, growth attained in the first year was on an average of 1.3 times in SVL (18.6 $\mathrm{mm}$ to $24.9 \mathrm{~mm})$, and 2.6 times in BM (240.5 to $627.9 \mathrm{mg}$ ). The growth rates are thus estimated to be about $0.04 \mathrm{~mm} /$ day in SVL and $2.2 \mathrm{mg} /$ day in BM.

Many individuals approached metamorphosis (>St. 63) within the first year. One individual was already at St. 64 in mid June, and 25\% of 16 individuals were at St. 64 or older in late July. This ratio increased to $60 \%(n=10)$ in late September, of which $67 \%$ were before metamorphosis (St. 66). However in late October, only one of nine larvae collected was at St. 64, and all the remaining larvae were still at St. 63. The first-year larvae of St. 64 or older were not much larger than the larvae at St. $63\left(\mathrm{t}_{47}=3.08, \mathrm{P}=0.003\right.$ in $\mathrm{SVL}, \mathrm{t}_{47}=2.30$, $\mathrm{P}=0.026$ in $\mathrm{BM})$.

Second-year larvae were observed from late February to late May, but were never found thereafter. There were several individuals at St. 63 and Sts. 65-68 (Table 1). The mean body size of larvae at St. 63 was larger than that of the larvae before overwintering $\left(\mathrm{t}_{20}=\right.$ 5.33, $\mathrm{P}<0.001$ in $\mathrm{SVL}, \mathrm{t}_{20}=4.41, \mathrm{P}<0.001$ in $\mathrm{BM})$. Among these second-year larvae, those approaching or completing metamorphosis (Sts. 65-68) were much larger than the firstyear larvae of the corresponding stages (St. 64-66; $\mathrm{t}_{11}=5.34, \mathrm{P}<0.001$ in $\mathrm{SVL}, \mathrm{t}_{11}=4.56$, $\mathrm{P}<0.001$ in $\mathrm{BM})$. In these second-year individuals, the one found in late February was just at metamorphosis (St. 68: SVL $=28.0 \mathrm{~mm}$, $\mathrm{BM}=655 \mathrm{mg}$ ) and represented the sole larva in our collection to have attained this stage. No larvae of the third year or older were found in the study site.

From these observations, the larval life history in the Kinko population is summarized as follows. Many of the first-year larvae approach metamorphosis within the year, from mid June in the earliest case, and mostly after attaining a SVL around $25 \mathrm{~mm}$ and BM about $590 \mathrm{mg}$ in late July. Some larvae overwinter once and continue growth, but all of them begin metamorphosis after late May at a SVL of about $28 \mathrm{~mm}$ and BM of about 
$655 \mathrm{mg}$, and never stay in the water thereafter.

\section{Diets}

Body mass was significantly correlated to SVL in both study sites (Takachiho: $\mathrm{r}_{92}=0.98$, $\mathrm{P}<0.001$; Kinko: $\left.\mathrm{r}_{95}=0.93, \mathrm{P}<0.001\right)$, and neither of the y-intercepts $\left(\mathrm{F}_{1,188}=0.19, \mathrm{P}=\right.$ $0.664)$ or slopes $\left(F_{1,187}=1.49, P=0.224\right)$ of the two equations differed significantly. In contrast, relationships of MW with SVL (Takachiho: $\mathrm{r}_{92}=0.93, \mathrm{P}<0.001$; Kinko: $\mathrm{r}_{95}=$ $0.90, \mathrm{P}<0.001)$ significantly differed in the y-intercepts $\left(\mathrm{F}_{1,188}=127.60, \mathrm{P}<0.001\right)$ though not in the slopes $\left(\mathrm{F}_{1,187}=0.08, \mathrm{P}=0.782\right)$ between the two populations. Thus, the larvae from both sites had similar BM at a given SVL, but Takachiho larvae were judged to have a wider mouth relative to SVL than the larvae from Kinko (see also Figs. 2B and C).

In order to examine the consequence of this difference in relative MW, we compared larval diets between the two sites. Stomach contents remained in 38 of a total of 70 stomachs in Takachiho (54.3\%), and in 61 of a total of 81 stomachs in Kinko (75.3\%). Thus, the larvae from Takachiho lacked prey items in their stomachs more frequently than did Kinko larvae (Fisher's exact test, $\mathrm{P}=0.007$ ). With the increase of developmental stage, larvae with an empty stomach correspondingly increased in both sites (Takachiho: $\mathrm{n}=11$, Spearman's $\mathrm{r}=0.93$, Kinko: $\mathrm{n}=11, \mathrm{r}=0.85 ; \mathrm{P}<0.001$ for both), but the tendency was more pronounced in Takachiho than in Kinko; $90.9 \%$ of larvae of st. 64 or older in Takachiho lacked contents in contrast to $35.3 \%$ in Kinko (Fisher's exact test, $\mathrm{P}=0.004$ ).

The number of prey per stomach was similar between the two sites $(1-14, \mathrm{x} \pm \mathrm{SD}=3.08 \pm 2.64$ in Takachiho, and 1-13, 3.87 \pm 2.36 in Kinko), but Takachiho consumed less variety of prey taxa than Kinko, and some prey taxa such as Coleoptera, Copepoda, Amphipoda, Acari, and Nematoda were found only in Kinko (Table 2). However, the proportion of these items was small, and predominating taxa (larval Diptera, larval Trichoptera, larval Ephemenoptera, and larval Plecoptera) were similar in the two sites, resulting in no significant difference in frequencies of occurrence of prey between the two sites (Fisher's exact test, $\mathrm{P}>0.05)$ in each item except for minerals. Minerals (pebbles and dirt) and plant materials (vegetation) occurred in $7.9 \%$ and $7.9 \%$, respectively, of Takachiho and $47.5 \%$ and $9.8 \%$ of Kinko stomachs examined.

Numeric proportions were similar between the two sites, and larval Diptera $28.2 \%$ in Takachiho and $23.7 \%$ in Kinko) was followed by larval Trichoptera $(23.9 \%$ and $13.6 \%$, respectively) and larval Ephemenoptera (17.9\% and $15.3 \%$, respectively), but Takachiho consumed a significantly larger number of larval Trichoptera than Kinko (Fisher's exact test, $\mathrm{P}=0.017$ ) (Table 2). In volume, Annelida made up the largest proportion, followed by larval Ephemenoptera, and larval Plecoptera in Takachiho, while the largest proportion was made up by larval Ephemenoptera, followed by larval Plecoptera, and larval Trichoptera in Kinko.

Interestingly, Kinko larvae more frequently contained minerals than Takachiho larvae (Fisher's exact test, $\mathrm{P}<0.001$ ), and numeric and volumetric proportions of minerals were also significantly larger in Kinko $(\mathrm{P}<0.001)$ (Table 2). When minerals and plant materials were excluded, Takachiho exhibited narrower niche breadths (1.736 in prey number and 1.206 in prey volume) than Kinko (2.025 and 1.790). Dietary overlap was high between the two sites in prey number (Morishita's $\mathrm{C} \lambda=0.991)$ but was low in volume (0.528), due to large volumetric percentage of earthworms in Takachiho ( $\mathrm{C} \lambda$ after removing Annelida= 0.989 in number and 0.942 in volume).

As shown above, Takachiho larvae were significantly larger in SVL and MW in each developmental stage. Moreover, mouth width relative to body size was significantly narrower in Kinko than in Takachiho. However, with the increase of body size, larvae from both sites correspondingly consumed larger prey similarly (Takachiho: $\mathrm{r}_{16}=0.602$ in mean prey length vs. SVL and $r_{16}=0.612$ in mean prey length vs. MW; Kinko: $\mathrm{r}_{40}=0.383$ and 0.434 ; 


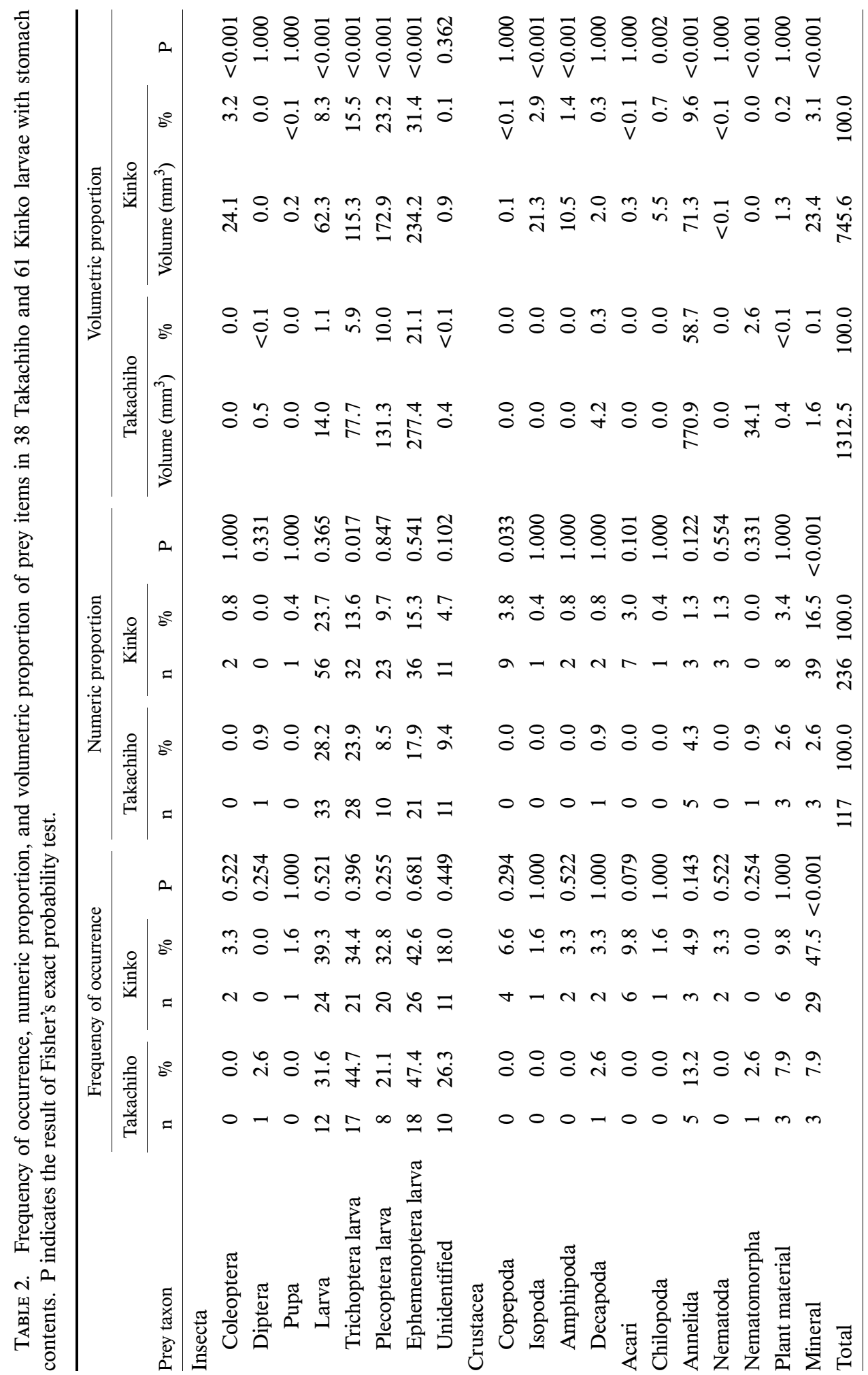


$\mathrm{P}<0.05$ for both), and smaller-mouthed Kinko larvae did not take smaller prey than widermouthed Takachiho larvae (ANCOVA: slopes: $\mathrm{F}_{1,56}=1.832, \mathrm{P}=0.180$; elevations: $\mathrm{F}_{1,57}=0.091$, $\mathrm{P}=0.762$ ).

\section{DISCUSSION}

\section{Time of egg-laying and hatching}

In this study, we could not find egg sacs or hatched larvae endowed with a large amount of yolk, and hence could not specify dates of oviposition or hatching in either of the two study sites. Sato (1943) reported that $H$. hirosei from Shikoku (formerly, Shikoku population of $H$. boulengeri: see Nishikawa et al., 2007) breeds in early to late May at a water temperature of 8-9 C, and larvae start hatching three to four weeks later. According to him, this species hatches at St. 44 (appearance of hindlimb bud) with a SVL of $13.5 \mathrm{~mm}$. The youngest larvae observed in the present study were already at Sts. 58 and 59 with a SVL of $19 \mathrm{~mm}$ in Takachiho, and Sts. 57 and 58 and $18.6 \mathrm{~mm}$ in Kinko, and must have spent some time since hatching. In Takachiho, the water temperature rose to 8-9 C (breeding temperature of $H$. hirosei in Shikoku: see above) in late March, and breeding males were found in mid April. Because Sato (2001) also found a dead female with ripe eggs in mid April near our study site, breeding in Takachiho seems to take place in April. In Kinko, water temperatures of 8-9 C were reached in late February, and a post-breeding male was seen in late March (our own observation and Sato, 2003). Therefore, the breeding season in Kinko seems to be in March, about one month earlier than in Takachiho. Probably, larvae after hatching hide themselves among pebbles for about one month while absorbing the yolk.

\section{Growth}

In both SVL and BM, the youngest larvae from Takachiho and Kinko were similar to each other, but thereafter, the larvae from Takachiho grew much faster than Kinko larvae (Fig. 4). In the first year, increments in
SVL and BM in Kinko accounted for $80.2 \%$ and $44.8 \%$, respectively, of those in Takachiho, and daily growth rates were also lower in Kinko, only $54.2 \%$ in SVL and $37.1 \%$ in BM of the rates observed in Takachiho.

The first-year larvae in Takachiho increased in SVL 1.53 times and in BM 3.33 times within 2.6-4.5 months from early May or mid June to September. However, in the subsequent 2.63.3 months between early September and early December, the growth decreased (1.08 times in SVL and 1.75 times in BM). From this seasonal change, the growth period of the first-year larvae in Takachiho could be divided into phases of rapid growth and subsequent fattening that respectively occur before and after early September. The rapid growth period in Kinko was about three months between mid April to late July, and SVL and $\mathrm{BM}$ increased on an average of 1.26 and 1.92 times during this period. The growth decreased thereafter and the larvae increased in SVL and BM only 1.06 and 1.35 times, respectively, during two to three months between late July to late September-late October. Compared with Takachiho, growth was less evident even in the rapidly growing period, and was earlier in the timing of its cessation. Increment in BM relative to SVL increment reversed as in Takachiho, but this change occurred earlier in late July, and fattening was less prominent in the fattening period than in Takachiho.

The body size at metamorphosis, which may affect the adult body size (Misawa and Matsui, 1999), differed between the two sites. Only five individuals of metamorphosing larvae (St. 68 ) in Takachiho included second and thirdyear-old larvae, but did not differ in size between the age classes. The size at metamorphosis is estimated to be about $39 \mathrm{~mm}$ in SVL and $1547 \mathrm{mg}$ in BM. In Kinko, only one metamorphosing individual of St. 68 with SVL of $28.0 \mathrm{~mm}$ and BM of $655 \mathrm{mg}$ was confirmed, but because these values were smaller than those of a younger larva of St. 67 (SVL= $33.5 \mathrm{~mm}$, BM $1275 \mathrm{mg}$ ), the normal size at metamorphosis would be slightly larger. If we 
estimate normal SVL at metamorphosis in Kinko to be about $31 \mathrm{~mm}$ (mean of St. 67 and 68 ), it is $79.5 \%$ of the corresponding size in Takachiho. This value approximates $82.5 \%$ found in adult males of the two sites (mean $\mathrm{SVL}=83.0 \mathrm{~mm}$ in Takachiho and $68.5 \mathrm{~mm}$ in Kinko: Nishikawa et al., 2003), and the size at metamorphosis is estimated to affect the adult body size as already reported in another hynobiid, H. kimurae Dunn, 1923 (Misawa and Matsui, 1999).

\section{Development}

The larvae in the two sites did not differ much in development in the period shortly after the first appearance. Namely, the larvae at St. 63 appeared 32-81 days after the first larval appearance in Takachiho, and this duration was similar to the corresponding period in Kinko (32 days), in the shortest case. However, subsequent development was retarded in Takachiho compared with Kinko. Most larvae remained at St. 63 in the first year, overwintered, and approached metamorphosis in the autumn of the second year. In contrast, most larvae in Kinko reached St. 64 or older in the autumn of the first year, and even overwintered individuals approached metamorphosis in the spring of the second year. Larvae of the third year or older were never observed in Kinko, while some larvae approached metamorphosis in the autumn of the third year, and even a four-year larva was observed in Takachiho.

This developmental difference resulted in great difference in the estimated larval period between the two sites; in Takachiho, the period (not including the time before appearance, see above) was 2.6-3.9 months in the shortest case, and mostly 15.1-16.7 months when the larvae overwintered once. The period was even longer, 22.5-23.8 to 27.6-28.9 months when the larvae overwintered twice, and 35.1-36.4 months after three overwinterings. In contrast, the larval period in Kinko was 1.9 months in the shortest case, normally up to 6.2 months, and was 13.2 months even after overwintering. Thus, the larval period in
Takachiho is much longer than in Kinko, about 1.4-2.1 times when compared in the shortest case, and 2.4-2.7 times in the normal case (comparison of Takachiho larvae which overwintered once and Kinko larvae metamorphosing without overwintering). The fouryear-old larva in Takachiho is estimated to have spent life in the water 2.7-2.8 times longer than the overwintered larvae in Kinko.

In a stream-breeding Japanese hynobiid, Onychodactylus japonicus (Houttuyn, 1782), larval life over three winters has been reported (Hayase and Yamane, 1982). However, no records of prolonged larval life have been reported for Hynobius species comparable to the Takachiho population of $H$. boulengeri, even though most of the others are known to overwinter (see below).

\section{Overwintering}

Larval overwintering has been found in all species of Japanese Hynobius except for $H$. katoi Matsui et al., 2004 (Sato, 1943; Sato et al., 1996; our personal observations), but the proportion of overwintering individuals varies highly from one population to another even within a species. In the lotic-breeders and some populations of lentic-breeders from cooler habitats, larvae tend to overwinter frequently. This tendency indicates that inhabiting flowing and/or cool still waters inhibits earlier metamorphosis.

In the present study, the fluctuation pattern of water temperatures differed between the two sites. The temperatures were much lower in Takachiho than in Kinko in the winter season, but this relationship was reversed in summer (Fig. 3). Although colder periods were longer in Takachiho than in Kinko, larvae from Takachiho actually grew more quickly than the larvae from Kinko, probably due to warmer water conditions in the summer season.

By contrast, larval development was much more retarded in Takachiho than in Kinko, although the two sites did not differ much in the water temperatures with respect to the timing of important events in the larval life. 
The temperature at the time of the first larval appearance in Kinko (about $13 \mathrm{C}$ ) was within the range of corresponding temperatures in Takachiho (12-16 C), and the temperatures at the time of metamorphosis largely overlapped between Takachiho and Kinko (17.5 $\mathrm{C}$ and 16.5 $\mathrm{C}$ in autumn, and 11.7-12 C and 9-14 C in spring, respectively). Thus, the difference in the environmental temperatures between the two sites seems to not be strong enough to affect the number of overwintering larvae or the timing of hatching and metamorphosis. Difference in the rate of larval development might be controlled by unknown genetic factors.

\section{Food}

Larvae of some lotic-breeding Hynobius species metamorphose quickly without feeding [some populations of $H$. naevius (Temminck and Schlegel, 1838) from Japan (Tanabe, 2002; Matsui et al., unpublished), and $H$. formosanus Maki, 1922 and possibly in $H$. sonani (Maki, 1922), both from Taiwan (Kakegawa et al., 1989)], and the timing of metamorphosis seems to be affected by food availability, as suggested by Newman (1998) and Bernardo and Agosta (2003).

Differential growth and development in the two sites resulted in difference in the overlapping period of the first year and older larvae. Such a period was estimated to last all of the first year after the first appearance of the hatched larvae from early May to mid June (about seven months) in Takachiho. Contrastingly, in Kinko, the co-existing season was estimated to last only one month from mid April at the appearance of the younger larvae to late May when overwintered older larvae began metamorphosis. Because a case of cannibalism has been reported in a Honshu population of $H$. boulengeri (Gose and Hayashi, 1983), these facts suggest a higher possibility of predation on the younger larvae by the older ones in Takachiho than in Kinko. However, we could not detect cannibalism in either site in Kyushu, even in the Takachiho population whose larvae are similar to larvae of the Honshu population in usually overwintering and having a relatively wide mouth.

From our data of larval food availability in the two sites, the larvae in Takachiho proved to have generally less food availability, but had more chance to take larger prey like earthworms than in Kinko. Thus, possession of a relatively wide larval mouth in Takachiho seems to have been selected not for cannibalism, but for not missing a limited food supply, and particularly for taking larger food like earthworms. The Kinko population contrastingly had relatively small larval mouth and shortened larval period. Little overlap of different generations in Kinko would not have favored a large mouth for cannibalism. Although food is less limited than in Takachiho, these larvae may metamorphose at the minimal size, which would result in a short larval period. Larval life history characteristics, as well as small adult body size in this population is unique among $H$. boulengeri and its ally, $H$. hirosei. Because the population is positioned at the terminal branch in an estimated phylogeny of $H$. boulengeri and $H$. hirosei (Nishikawa et al., 2001, 2005, 2007), such traits might be genetically determined and newly acquired in the evolution of this species.

As reviewed by Bernardo and ReaganWallin (2002) and Bernardo and Agosta (2003), various environmental and genetic factors are involved in the larval life history and body size variations. In the present study, we have elucidated the differential pattern of larval life history in two populations of $H$. boulengeri in Kyushu. However, there still remain many questions such as actual timing of breeding, and the factors that determine individually different times of overwintering. In order to solve these problems, further field studies, as well as laboratory studies including rearing larvae from both sites under identical conditions, are required.

\section{ACKNOWLEDGEMENTS}

We would like to thank K. Sakata, M. 
Sakamoto, S. Okada, S. Sato, and T. Shimada for help in collecting specimens and field information. We are also grateful to T. Hikida for help in statistical analyses, and S. Tanabe, S. Sato, and Y. Misawa for daily discussions. This work was partly supported by a grant from the Fujiwara Natural History Foundation and Showa Seitoku Memorial Foundation to K. Nishikawa.

\section{LITERATURE CITED}

BERnARDO, J. 1994. Experimental analysis of allocation in two divergent, natural salamander populations. American Naturalist 143: 14-38.

Bernardo, J. ANd Agosta, S. J. 2003. Determinants of clinal variation in life history of dusky salamanders (Desmognathus ocoee): prey abundance and ecological limits on foraging time restrict opportunities for larval growth. Journal of Zoology, London 259: 411-421.

Bernardo, J. ANd REAGAN-Wallin, N. L. 2002. Plethodontid salamanders do not conform to general rules for ectotherm life histories: insights from allocation models about why simple models do not make accurate predictions. Oikos 97: 398-414.

Berven, K. A. 1982. The genetic basis of altitudinal variation in the wood frog Rana sylvatica $\mathrm{I}$. An experimental analysis of life history traits. Evolution 36: 962-983.

BERVEN, K. A. AND GILl, D. E. 1983. Interpreting geographic variation in life history traits. American Zoologist 23: 85-97.

BRUCE, R. C. 1989. Life history of the salamander Desmognathus monticola, with a comparison of the larval periods of $D$. monticola and $D$. ochrophaeus. Herpetologica 45: 144-155.

Castanet, J. And Smirina, E. M. 1990. Introduction to the skeletochronological method in amphibian and reptiles. Annales des Sciences Naturelles Zoologie, Paris. Série 13 11: 191196.

Dunham, A. E. 1983. Realized niche overlap. Resource abundance and intensity of interspecific competition. p. 261-280. In: R. B. Huey, E. R. Pianka, and T. W. Schoener (eds.), Lizard Ecology: Studies of a Model Organism. Har- vard University Press, Cambridge.

Eden, C. J., Whiteman, H. H., Duobinis-Gray, L., AND Wissinger, S. A. 2007. Accuracy assessment of skeletochronology in the Arizona tiger salamander (Ambystoma tigrinum nebulosum). Copeia 2007: 471-477.

Ento, K. AND Matsui, M. 2002. Estimation of age structure by skeletochronology of a population of Hynobius nebulosus in a breeding season (Amphibia, Urodela). Zoological Science 19: 241-247.

Gose, K. And Hayashi, Y. 1983. The ecology and conservation of Hynobius boulengeri. Iden 37: 57-61 (in Japanese)

Hayase, N. and Yamane, S. 1982. Life history during the aquatic life period of a salamander, Onychodactylus japonicus (Houttuyn), at Mts. Tsukuba, Ibaraki, Japan. Japanese Journal of Ecology 32: 395-403 (in Japanese)

IwASAKI, F. AND WaKahara, M. 1999. Adaptable larval life histories in different populations of the salamander, Hynobius retardatus, living in various habitats. Zoological Science 16: 667-674.

Iwasawa, H. ANd Yamashita, K. 1991. Normal stages of development of a hynobiid salamander, Hynobius nigrescens Stejneger. Japanese Journal of Herpetology 14: 39-62.

JUTERBOCK, J. E. 1990. Variation in larval growth and metamorphosis in the salamander Desmognathus fuscus. Herpetologica 46: 291-303.

KaKegawa, M., IIZuKa, K., and KuZumi, S. 1989. Morphology of egg sacs and larvae just after hatching in Hynobius sonani and H. formosanus from Taiwan, with an analysis of skeletal muscle protein compositions. p. 147-155. In: M. Matsui, T. Hikida, and R. C. Goris (eds.), Current Herpetology in East Asia. Herpetological Society of Japan, Kyoto.

Matsui, M. 2000. Hynobius boulengeri from Kyushu and Honshu regions. p. 110-111. In: Environmental Agency of Japan (ed.), The Red Data Book of Japan-Amphibians and Reptiles 2000. Japan Wildlife Research Center, Tokyo. (in Japanese)

Misawa, Y. ANd Matsui, M. 1997. Larval life history variation in two populations of the Japanese salamander Hynobius kimurae (Amphibia, Urodela). Zoological Science 14: 257-262. 
Misawa, Y. and Matsui, M. 1999. Age determination by skeletochronology of the Japanese salamander Hynobius kimurae (Amphibia, Urodela). Zoological Science 16: 845-851.

Morishita, M. 1959. Measuring of interspecific association and similarity between communities. Memoirs of the Faculty of Science, Kyushu University. Series E (Biology) 3: 65-80.

Newman, R. A. 1998. Ecological constraints on amphibian metamorphosis: interactions of temperature and larval density with responses to changing food level. Oecologia 115: 9-16.

Nishikawa, K., Matsui, M., Tanabe, S., and Sato, S. 2001. Geographic enzyme variation in a Japanese salamander, Hynobius boulengeri Thompson (Amphibia: Caudata). Herpetologica 57: 281-294.

Nishikawa, K., Matsui, M., Tanabe, S., and SaKamoto, M. 2003. Occurrence of the lotic breeding Hynobius salamander (Amphibia, Urodela) from the Amakusa Islands, Japan. Current Herpetology 22: 1-8.

NishiKawa, K., Matsui, M., and Tanabe, S. 2005. Biochemical phylogenetics and historical biogeography of Hynobius boulengeri and H. stejnegeri (Amphibia: Caudata) from the Kyushu region, Japan. Herpetologica 61: 54-62.

Nishikawa, K., Matsui, M., Tanabe, S., and SATo, S. 2007. Morphological and allozymic variation in Hynobius boulengeri and $H$. stejnegeri (Amphibia: Urodela: Hynobiidae). Zoological Science 24: 752-766.

SAS. 1990. SAS/STAT User's Guide. SAS Institute Incorporation, Cary.

Sato, I. 1943. A Monograph of the Tailed Batrachians of Japan. Nippon Shuppan-sha, Osaka. (in Japanese)
Sato, S. 1954. On Pachypalaminus boulengeri Thompson from Kyushu. Zoological Magazine, Tokyo 63: 195-199 (in Japanese)

Sato, S. 2001. From my old field notes (1) The first encounter with Hynobius boulengeri (Caudata: Hynobiidae) in Kyushu. Bulletin of the Herpetological Society of Japan 2001: 8-11 (in Japanese)

Sato, S. 2003. From my old field notes (2) The first encounter with Hynobius boulengeri (Caudata: Hynobiidae) in the Osumi Peninsula. Bulletin of the Herpetological Society of Japan 2003: 8-14 (in Japanese)

Sato, T., Kusano, T., Matsui, M., Tanaka, K., Misawa, Y., AND AKita, Y. 1996. Salamanders. p. 11-20. In: S. Sengoku, T. Hikida, M. Matsui, and K. Nakaya (eds.), The Encyclopedia of Animals in Japan 5, Amphibians, Reptiles, Chondrichthyes. Heibonsya, Tokyo. (in Japanese)

Shannon, C. E. And Weaver, W. 1949. The Mathematical Theory of Communication. University of Illinois Press, Illinois.

Smirina, E. M. 1994. Age determination and longevity in amphibians. Gerontology 40: 133146.

Tanabe, S. 2002. Hynobius naevius (Amphibia). p. 164-165. In: Editorial Committee of Red Data Book of Kochi Prefecture (ed.), Red Data Book of Kochi Prefecture (Animals). Kochi Prefecture, Kochi. (in Japanese)

Tilley, S. G. ANd Bernardo, J. 1993. Life history evolution in plethodontid salamanders. Herpetologica 49: 154-163. 